Original Article

\title{
Study of Germination Efficiency and Temperature/Drowning Resistance in some Ornamental Plants treated with Ultra High Dilute Compounds
}

\author{
Faeze Mirzajani 1, Mitra Aelaei 1, Hassan Rezadoost 2, Fateme Mirzajani 3, \\ 1 - Department of Horticulture, Faculty of Agriculture, University of Zanjan, Zanjan, 45371-38791, Iran. \\ 2 - Department of Phytochemistry, Medicinal Plants and Drug Research Institute, Shahid Beheshti University, \\ G.C., Tehran, Iran. \\ 3 - Department of Biochemistry, Protein Research Center, Shahid Beheshti University, G.C., Tehran, Iran. \\ * f mirzajani@sbu.ac.ir; fateme.mirzajani@gmail.com - https://orcid.org/0000-0002-6797-4243
}

\begin{abstract}
Background: The ultra-high dilutions (UHDs) can be used for decreasing stress conditions causing by climate variations. The present research investigated the effects of ultra-high dilutions (UHDs) on some ornamental plants, germination, and hormonal variations. Methods: In order to study the effect of UHDs (Calendula officinalis Calen. and Arnica montana Arn.) on the physiological, primary metabolite, and hormonal variations of the Oryza sativa L. (rice), 104 experiments were designed and statistically analyzed using the Design Expert 7.0.1 software over the general factorial design methodology. Two qualitative factors, including the UHDs/placebo usage and the type of plant usage, and two quantitative factors, including temperature and irrigation, were studied. The validated analysis was subjected to more extended studies on the variations in physiological growth, carbohydrate, protein content, and levels of plant hormones, including gibberellic acids, indole acetic acid, abscisic acid, and salicylic acid. Results: The statistical analysis resulted in a prediction model which was more than 75\% correlates with experimental results. The results showed that the UHDs increased the carbohydrate and protein content of seedlings. Also, compared to placebo, the levels of hormones GA3 and IAA in all samples increase, and the amount of GA4 decreases. The amount of ABA and SA hormones in S. officinalis increased under UHDs treatment while decreasing in the other two samples. Conclusion: The use of UHDs leads to an increase in the production of carbohydrate and protein content. Moreover, it causes significant variations in the growth-inducing hormone and increases the tolerance of seeds under higher/lower temperatures and draught/drowning. The results of this study open up a window to reduce germination survival and increase their resistance to sudden climate change.
\end{abstract}

Keywords: Ornamental plants, Plant hormones, Stress condition, Ultra high dilutions.

\section{Introduction}

Climate change leads to an increase/decrease in the length and amount of temperature and light exposure during the crop season, forming the environmental stresses conditions such as drought or drowning and changing the amount of carbon dioxide/oxygen in the environment [1]. Following these variations, the quality of germination and growth, the efficiency of photosynthesis and crop production, the growth and establishment of weeds are change. The destructive effects of sudden climate change and its consequences, compared to other challenges facing the agricultural industry such as diseases, pests, weeds, and pollution of water and soil resources, are difficult to control and to compensate. In many cases, it is also is irreparable [2].

Sudden cold and heavy rain/snow at the end of winter and the beginning of spring are some of the destructive effects of sudden climate change [3]. This period is the beginning of the cultivation and

OPEN ACCESS 
germination of many plants and ornamental species like Portulaca grandiflora, Salvia officinalis, Rudbeckia hirta, and Catharanthus roseus [4,5]. However, a drastic decrease in temperature and rain/snow in one night will damage the buds or young crops. Under these conditions, the buds are either damaged or destroyed. It may cause reduces the ability to grow and the efficiency of photosynthesis or increases the risk of pests and disease infection. So, many plants become stressed during these seasons or need to be planted in greenhouses and controlled conditions. Both are costly, and the plant is grown in an unnatural environment [6].

While standard methods of dealing with crop damage, in many cases, such as pest and weed control, recommend pesticides/herbicides and fertilizers, it does not provide a solution to control the damage caused by climate change $[7,8]$. So, it seems necessary to use new methods to maintain the product. One of these methods is ultra-high diluted compounds (UHDs) to deal with climate change and its resulting damage. The researchers used these compounds to increase the length of the stem of Pisum sativum L [9], to improve the germination and viability of wheat germ under drought and salinity stress [10], to increase the resistance of Triticum aestivum L to ultraviolet radiation [11], to control Sclerotinia sclerotiorum infection on Phaseolus vulgaris L [12], to control Meloidogyne incognita population in Solanum lycopersicum L and to increase the activity of its defense enzymes [13-15]. Together, it led to a cessation of growth and removal of Alternaria solani mycelium on Solanum lycopersicum L, improving germination and physiological characteristics of Triticum aestivum [16-20] and improvement of germination and the rooting of Oryza sativa [19,20]. Despite these reports, no report has yet been published on controlling climate change, such as temperature variations or drowning/drought conditions that affect seed germination and the survival of the buds. This study investigates the rate of germination and survival of Portulaca grandiflora, Salvia officinalis, Rudbeckia hirta, and Catharanthus roseus buds and their hormonal variations under the temperature and irrigation variations and the treatment of UHDs for the first time.

\section{Materials and Methods:}

\section{Materials and growth conditions}

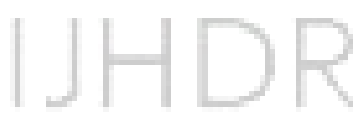

Seeds (3 months old harvested) of Portulaca grandiflora, Salvia officinalis, Rudbeckia hirta, and Catharanthus roseus were obtained from the Pakan Bazr Co., Isfahan, Iran. The UHD's of Calendula officinalis (Calen. 30C) and Arnica montana (Arn. 200C) were purchased from DHU Co., Germany. Both UHDs were in solid granules in $1 \mathrm{~mm}$. Placebo (as a control material) was obtained in the same size of granules from DHU Co., Germany. Ultrapure ICP-MS grade water, Sartorius Co., Germany, was used throughout the experiment.

The solutions of granules and placebo were used in the experiments and treatments at a ratio of 1 globule per $10 \mathrm{~mL}$ ultrapure water. The UHD's were dissolved in water for $20 \mathrm{~min}$ and freshly used 30 min after preparation. A conventional laboratory culture was performed in a sterile condition, while normal culture is in non-sterile conditions. So, two study groups were noted: non-sterile and sterile conditions. In the sterilization process, the autoclave was applied at $121^{\circ} \mathrm{C}$ at a pressure of 1.1 bar for $20 \mathrm{~min}$. Using UHDs is briefly referred to the general principles of the previous publication [19]. Seedlings (10 seeds) were placed on Petri dishes (ID: $7 \mathrm{~cm}$ ) with $10 \mathrm{ml}$ of water based on the experiments described in Table 1. In the first stage of seed germination, in each petri dish (containing 10 seeds), $10 \mathrm{~mL}$ of the Calen. solution was used (Figure 1). Petri dishes were kept at $27 \pm 0.5^{\circ} \mathrm{C}$ in a dark place for four-ten days. After that, for the growth of the seedlings and production of chlorophyll, 
the dishes were transferred into light and kept for four more days (second stage of growth). The 1 mL of UHD Arn. solution was applied before transferring the Petri dishes into the light.

Table 1: Levels of factors considered in seed germination experimental designs.

\begin{tabular}{|c|c|c|c|c|c|c|c|c|}
\hline \multicolumn{5}{|c|}{ Factors Levels } & \multirow{2}{*}{ Unit } & \multirow{2}{*}{ Code } & \multirow{2}{*}{ Factor } & \multirow{2}{*}{ Condition } \\
\hline-2 & -1 & $\mathbf{0}$ & +1 & +2 & & & & \\
\hline-1 & 7 & 18 & 28 & 40 & ${ }^{\circ} \mathrm{C}$ & $\mathbf{A}$ & Temperature & \multirow{2}{*}{ Quantitative } \\
\hline 1 & 2 & 4 & 6 & 7 & $\mathbf{m L}$ & B & Irrigation & \\
\hline C. roseus & R. hirta & \multicolumn{2}{|c|}{ P. grandiflora } & S. officinalis & - & C & Plant & \multirow{2}{*}{ Qualitative } \\
\hline \multicolumn{2}{|c|}{ Non-UHDs } & \multicolumn{3}{|c|}{ UHDs } & - & D & Treatment & \\
\hline
\end{tabular}

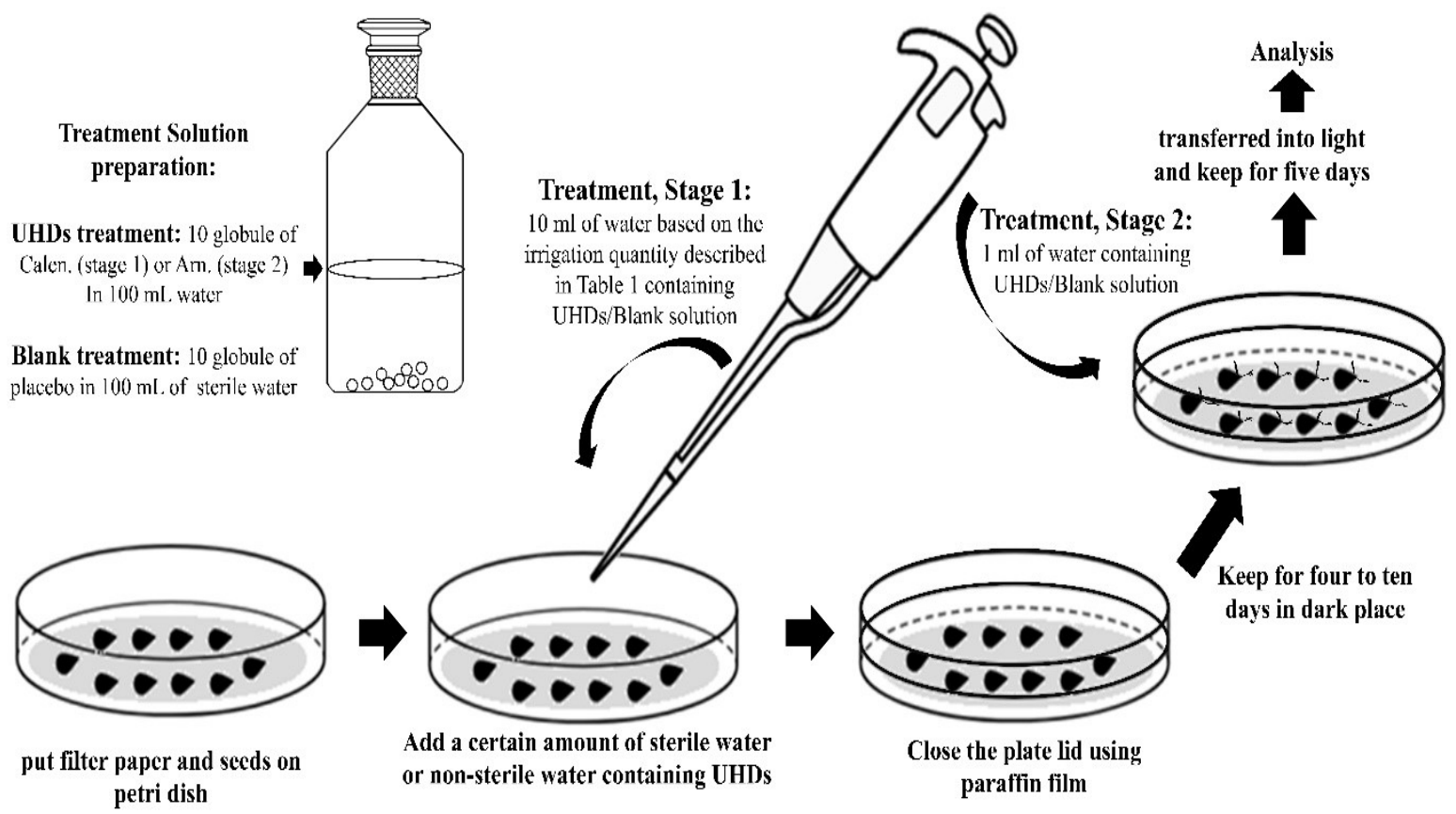

Fig 1 - Seed germination study schematic.

To investigate the effects of UHD treatments and the sterilization conditions on the seedlings, the Design Expert 7.0.1 software and the general factorial design methodology were applied. Two quantitative (A and $\mathrm{B}$ ) and two qualitative factors ( $C$ and $\mathrm{D}$ ) were studied on UHD's treatments and growing conditions (Table 1). To this end, 104 experiments (in three replications) were designed (Table 2). Experiments were designed based on the methodology of the general factorial design algorithm to evaluate two quantitative factors, including the temperature (Factor A) and irrigation (Factor B), and the two qualitative factors, including the UHDs/placebo usage (Factor D), and the type of the plant (Factor C). Factors A and D were selected to study the effects of UHDs on seed germination and growth. The sterilization conditions (applying the high temperature and pressure or sterilizing solutions) lead to changes in the seed's nature and the properties of the UHDs. 
Table 2: General factorial design methodology experimental design for the study of seedlings.

\begin{tabular}{|c|c|c|c|c|c|c|c|c|c|c|c|c|c|}
\hline \multirow{2}{*}{ एँ } & \multirow{2}{*}{$\dot{\Xi}$} & \multicolumn{2}{|c|}{$\begin{array}{c}\text { Quantified } \\
\text { factor }\end{array}$} & \multicolumn{2}{|c|}{ Qualified factor } & \multirow{2}{*}{ 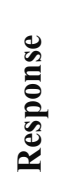 } & \multirow{2}{*}{ 远 } & \multirow{2}{*}{$\dot{\Xi}$} & \multicolumn{2}{|c|}{$\begin{array}{l}\text { Quantified } \\
\text { factor }\end{array}$} & \multicolumn{2}{|c|}{ Qualified factor } & \multirow{2}{*}{ 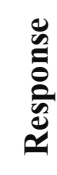 } \\
\hline & & $\begin{array}{c}\text { Temp } \\
\left({ }^{\circ} \mathrm{C}\right)\end{array}$ & $\begin{array}{c}\text { Water } \\
(\mathrm{mL})\end{array}$ & Plant & Treat & & & & $\begin{array}{c}\text { Temp } \\
\left({ }^{\circ} \mathrm{C}\right)\end{array}$ & $\begin{array}{c}\text { Water } \\
(\mathrm{mL})\end{array}$ & Plant & Treat & \\
\hline 93 & 1 & 18 & 2 & C. roseus & N-UHDs & $\overline{0}$ & 39 & 53 & 18 & 4 & R. hirta & UHDs & 3 \\
\hline 31 & 2 & 7 & 4 & R. hirta & UHDs & 2 & 29 & 54 & 7 & 6 & R. hirta & UHDs & 8 \\
\hline 63 & 3 & 28 & 4 & S. officinalis & N-UHDs & 0 & 53 & 55 & 7 & 2 & S. officinalis & N-UHDs & 2 \\
\hline 12 & 4 & 18 & 4 & S. officinalis & UHDs & 9 & 78 & 56 & 18 & 4 & P. grandiflora & N-UHDs & 2 \\
\hline 46 & 5 & 40 & 1 & C. roseus & UHDs & 0 & 88 & 57 & 18 & 4 & R. hirta & N-UHDs & 4 \\
\hline 37 & 6 & -1 & 4 & R. hirta & UHDs & 3 & 77 & 58 & 18 & 4 & P. grandiflora & N-UHDs & 0 \\
\hline 96 & 7 & -1 & 4 & C. roseus & N-UHDs & 0 & 8 & 59 & 18 & 7 & S. officinalis & UHDs & 10 \\
\hline 18 & 8 & -1 & 4 & P. grandiflora & N-UHDs & 3 & 84 & 60 & 40 & 4 & R. hirta & N-UHDs & 0 \\
\hline 68 & 9 & 18 & 6 & P. grandiflora & N-UHDs & 3 & 76 & 61 & 18 & 4 & P. grandiflora & N-UHDs & 4 \\
\hline 98 & 10 & -1 & 1 & C. roseus & N-UHDs & 0 & 20 & 62 & 18 & 1 & P. grandiflora & UHDs & 5 \\
\hline 44 & 11 & -1 & 4 & C. roseus & UHDs & 0 & 101 & 63 & 18 & 4 & C. roseus & N-UHDs & 1 \\
\hline 102 & 12 & 18 & 4 & C. roseus & N-UHDs & 1 & 3 & 64 & 7 & 6 & S. officinalis & UHDs & 8 \\
\hline 56 & 13 & 28 & 6 & S. officinalis & N-UHDs & 0 & 66 & 65 & 7 & 2 & P. grandiflora & N-UHDs & 2 \\
\hline 30 & 14 & 28 & 6 & R. hirta & UHDs & 6 & 23 & 66 & 18 & 4 & P. grandiflora & UHDs & 9 \\
\hline 80 & 15 & 28 & 2 & R. hirta & N-UHDs & 0 & 86 & 67 & 18 & 7 & R. hirta & N-UHDs & 2 \\
\hline 58 & 16 & 40 & 4 & S. officinalis & N-UHDs & 0 & 65 & 68 & 18 & 4 & S. officinalis & N-UHDs & 0 \\
\hline 57 & 17 & -1 & 4 & S. officinalis & N-UHDs & 0 & 34 & 69 & 18 & 7 & R. hirta & UHDs & 7 \\
\hline 35 & 18 & 18 & 4 & R. hirta & UHDs & 4 & 64 & 70 & 18 & 4 & S. officinalis & N-UHDs & 1 \\
\hline 94 & 19 & 7 & 6 & C. roseus & N-UHDs & 0 & 25 & 71 & 18 & 4 & P. grandiflora & UHDs & 7 \\
\hline 42 & 20 & 7 & 6 & C. roseus & UHDs & 1 & 21 & 72 & 18 & 7 & P. grandiflora & UHDs & 5 \\
\hline 16 & 21 & 7 & 6 & P. grandiflora & UHDs & 6 & 100 & 73 & 18 & 4 & C. roseus & N-UHDs & 0 \\
\hline 87 & 22 & 18 & 4 & R. hirta & N-UHDs & 3 & 67 & 74 & 28 & 2 & P. grandiflora & N-UHDs & 4 \\
\hline 41 & 23 & 28 & 2 & C. roseus & UHDs & 10 & 104 & 75 & 18 & 4 & C. roseus & N-UHDs & 0 \\
\hline 91 & 24 & 18 & 4 & R. hirta & N-UHDs & 2 & 27 & 76 & 7 & 2 & R. hirta & UHDs & 7 \\
\hline 61 & 25 & 18 & 4 & S. officinalis & N-UHDs & 0 & 69 & 77 & 28 & 6 & P. grandiflora & N-UHDs & 5 \\
\hline 1 & 26 & 7 & 2 & S. officinalis & UHDs & 2 & 17 & 78 & 28 & 6 & P. grandiflora & UHDs & 8 \\
\hline 74 & 27 & 18 & 4 & P. grandiflora & N-UHDs & 5 & 79 & 79 & 7 & 2 & R. hirta & N-UHDs & 0 \\
\hline 75 & 28 & 18 & 4 & P. grandiflora & N-UHDs & 8 & 10 & 80 & 18 & 4 & S. officinalis & UHDs & 3 \\
\hline 51 & 29 & 18 & 4 & C. roseus & UHDs & 0 & 13 & 81 & 18 & 4 & S. officinalis & UHDs & 6 \\
\hline 47 & 30 & 18 & 7 & C. roseus & UHDs & 0 & 22 & 82 & 18 & 4 & P. grandiflora & UHDs & 7 \\
\hline 81 & 31 & 7 & 6 & R. hirta & N-UHDs & 0 & 60 & 83 & 18 & 7 & S. officinalis & UHDs & 0 \\
\hline 83 & 32 & -1 & 4 & R. hirta & N-UHDs & 0 & 4 & 84 & 28 & 6 & S. officinalis & UHDs & 0 \\
\hline 49 & 33 & 18 & 4 & C. roseus & UHDs & 2 & 89 & 85 & 18 & 4 & R. hirta & N-UHDs & 2 \\
\hline 5 & 34 & -1 & 4 & S. officinalis & UHDs & 5 & 54 & 86 & 28 & 2 & S. officinalis & N-UHDs & 0 \\
\hline 103 & 35 & 18 & 4 & C. roseus & N-UHDs & 0 & 36 & 87 & 18 & 4 & R. hirta & UHDs & 0 \\
\hline 15 & 36 & 28 & 2 & P. grandiflora & UHDs & 7 & 43 & 88 & 40 & 6 & C. roseus & UHDs & 10 \\
\hline 6 & 37 & 40 & 4 & S. officinalis & UHDs & 0 & 26 & 89 & 18 & 1 & P. grandiflora & UHDs & 5 \\
\hline 97 & 38 & 40 & 4 & C. roseus & N-UHDs & 1 & 45 & 90 & 40 & 1 & C. roseus & UHDs & 10 \\
\hline 82 & 39 & 28 & 6 & R. hirta & N-UHDs & 0 & 33 & 91 & 18 & 2 & R. hirta & UHDs & 2 \\
\hline 55 & 40 & 7 & 6 & S. officinalis & N-UHDs & 4 & 72 & 92 & 18 & 2 & P. grandiflora & N-UHDs & 0 \\
\hline 85 & 41 & 18 & 1 & R. hirta & UHDs & 4 & 48 & 93 & 18 & 4 & C. roseus & UHDs & 3 \\
\hline 50 & 42 & 18 & 4 & C. roseus & UHDs & 1 & 19 & 94 & 40 & 4 & P. grandiflora & UHDs & 6 \\
\hline 24 & 43 & 18 & 4 & P. grandiflora & UHDs & 2 & 52 & 95 & 18 & 4 & C. roseus & UHDs & 2 \\
\hline 7 & 44 & 18 & 1 & S. officinalis & UHDs & 6 & 71 & 96 & 40 & 4 & P. grandiflora & N-UHDs & 0 \\
\hline 92 & 45 & 7 & 2 & C. roseus & N-UHDs & 0 & 9 & 97 & 18 & 4 & S. officinalis & UHDs & 10 \\
\hline 59 & 46 & 18 & 1 & S. officinalis & N-UHDs & 0 & 62 & 98 & 18 & 4 & S. officinalis & N-UHDs & 0 \\
\hline 32 & 47 & 40 & 4 & R. hirta & UHDs & 1 & 70 & 99 & -1 & 4 & & N-UHDs & 1 \\
\hline 11 & 48 & 18 & 4 & S. officinalis & UHDs & 8 & 90 & 100 & 18 & 4 & R. hirta & N-UHDs & 0 \\
\hline 99 & 49 & 18 & 7 & C. roseus & UHDs & 0 & 28 & 101 & 28 & 4 & R. hirta & UHDs & 2 \\
\hline 40 & 50 & 7 & 2 & C. roseus & UHDs & 2 & 2 & 102 & 28 & 6 & S. officinalis & UHDs & 0 \\
\hline 38 & 51 & 18 & 4 & R. hirta & UHDs & 2 & 73 & 103 & 18 & 6 & & N-UHDs & 0 \\
\hline 14 & 52 & 7 & 2 & P. grandiflora & UHDs & 5 & 95 & 104 & 28 & 7 & C. roseus & N-UHDs & 0 \\
\hline
\end{tabular}

Std.: Standard randomization

Ran.: Run order

UHDs: Ultra-high diluted compound treatment N-UHDs: Non-UHDs treatment (or negative control),

Response: The amounts of healthy seedlings 
So, factor A was chosen to study the effect of sterilization and UHDs conditions on germination and growth. The UHD's treatments (Factor D) encompassed two stages. The Calen. treatment was used at the first stage of seedling when the seeds were put in water and dark conditions. The Arn. dilution was used in the second stage before transforming the seedlings into the light. Placebo was used instead of UHDs in the corresponding conditions in a similar procedure. Tools, seeds, and water were sterilized in all tests designed in sterile conditions. A total of 104 experiments were designed. Each one was conducted in three random replications based on the standard randomization order (Table 2). The amounts of healthy seedlings were used as a response.

The analysis of variance (ANOVA) report is available either with or without annotation and includes a complete analysis of variance, prediction equations, and case statistics. The implication of the F-value depends on the degree of freedom of the model. Data were analyzed with an accuracy of $99 \% \leq$. The Fprobability $\leq 0.0001$ was considered to be statistically significant.

R-Squared and adjusted R-Squared values were evaluated as the accuracy extent of the experimental results and the statistical model, respectively. The standard error of the estimation was evaluated for the standard deviation of the residuals. After statistical analysis and determination of the most effective laboratory conditions, chemical and physiological studies were performed. The accuracy and validity of the results and graphs were determined using MSTAT-C software. Different mean values were mentioned with letters $(\mathrm{a}, \mathrm{b}, \mathrm{c}$ and $\mathrm{ab})$ at $\mathrm{P}$-value $<0.05$.

\section{Physiological analysis and growth quality assay}

To conduct a physiological analysis and the growth quality assay, the buds were dried individually by freeze dryer (333Bi5, DorsaTech Co., Iran) at $-80^{\circ} \mathrm{C}$, for $24 \mathrm{~h}$. For the total carbohydrate content, $100 \mathrm{mg}$ of dried powder was extracted using ethanol $80 \%$ for $60 \mathrm{~min}$. Five $\mathrm{mL}$ of $\mathrm{HCl} 1.1 \%$ was added into the supernatant, and the mixtures were heated in a water bath $\left(97^{\circ} \mathrm{C}\right)$ for $30 \mathrm{~min}$. The samples $(1 \mathrm{~mL})$ were mixed with $5 \mathrm{~mL}$ of ice-cold anthrone reagent (72\% sulfuric acid containing $0.2 \%$ anthrone) and reheated $(11 \mathrm{~min})$. The solutions absorbance was measured at $630 \mathrm{~nm}$. The total protein content of 0.1 $\mathrm{g}$ of the bud tissues were extracted over TRIzol reagent protocol (Molecular Research Center, Inc., Cincinnati, OH, USA). Thereafter, the protein concentration was determined according to the Bradford assay kit (BioRad Co., Hercules, CA, USA) in the comparison with BSA as the standard [21, 22].

\section{Metabolite extraction and Quantification by HPLC}

For Hormonal and enzymatic analysis, $R$. hirta and $S$. officinalis was chosen because of its higher amounts of biomass and influenced under the UHDs treatment. In each case, a $0.1 \pm 0.001 \mathrm{~g}$ samples were dried overnight in a freeze drier at using a vacuum CentriVap concentrator (Labconco, MO, USA) at $40{ }^{\circ} \mathrm{C}$ and extracted with $1 \mathrm{~mL}$ of $\mathrm{MeOH}: \mathrm{H}_{2} \mathrm{O}$ (in the ratio of 7:3) using $1200 \mathrm{~W}$ sonication for $10 \mathrm{~min}$. Supernatant were removed (centrifuged at16,000 g and $4{ }^{\circ} \mathrm{C}$ for $5 \mathrm{~min}$ ) and dried in speed vac. After drying, $100 \mu \mathrm{L}$ of MeOH and analyzed by HPLC (Waters Co., USA), using a Luna Phenyl-Hexyl column (150 $\times 4.6 \mathrm{~mm}, 5 \mu \mathrm{m}, 100 \mathrm{~A}^{\circ}$; Phenomenex, Aschaffenburg, Germany). Formic acid (0.05\%, v/v) and $\mathrm{MeOH}$ with $0.05 \%(\mathrm{v} / \mathrm{v})$ of formic acid were employed as mobile phases $\mathrm{A}$ and $\mathrm{B}$, respectively. The elution profile was: 0-10 min, $42-55 \%$ B in A; $10-13$ min, $55-100 \%$ B; $13-15$ min $100 \%$ B; $15-18$ min $100-$ $42 \% \mathrm{~B}$ in $\mathrm{A}$; and $18.1-30 \mathrm{~min} 42 \% \mathrm{~B}$ in $\mathrm{A}$. The mobile phase flow rate was $1.1 \mathrm{~mL} / \mathrm{min}$. Injection volume was $20 \mu \mathrm{L}$ and the detection wavelength of $280 \mathrm{~nm}(21-23)$. 


\section{Results}

As mentioned in the previous sections, the purpose of this study is to investigate the germination rate and viability of buds under variable temperature and irrigation conditions treated with UHDs. In addition, the germinations total protein and carbohydrate content and the hormonal variations were studied. According to the statistical study described in the previous section, based on the conformity of the designed model and the experimental results (Table 3), the response prediction surfaces are proposed by the software (Figure 2). Curved surfaces were drawn to investigate the germination behavior of seeds under designed conditions. These superficial responses can be studied and analyzed on two-dimensional curves (figure $2 \mathrm{a}$ and $2 \mathrm{~b}$ ) or three-dimensional curves (figure $2 \mathrm{c}$ and $2 \mathrm{~d}$ ). In Figures $2 \mathrm{a}$ and $2 \mathrm{~b}$, the response rate (germination) is related to the behavior of the plant type and temperature and irrigation rate, respectively. As can be seen, the overall germination efficiency under UHDs treatment conditions increased in all plants compared to untreated conditions. This is especially true for $C$. roseus seeds. Figure 2a presents the highest and lowest germination efficiencies under the influence of UHDs, which are 2.9 (in the case of $S$. officinalis) and 0.1 (in the case of $C$. roseus), respectively. These values are -1.1 and -0.9 in untreated conditions, respectively. Based on this, it can be concluded that germination efficiency increases by about 3 times in UHDs. Also, S. officinalis and $P$. grandiflora under the UHDs conditions have the highest germination efficiency at $-1{ }^{\circ} \mathrm{C}$ and $40{ }^{\circ} \mathrm{C}$, respectively. The lowest germination efficiency under UHDs treatment is related to $C$. roseus germinations at $-1{ }^{\circ} \mathrm{C}$. On the other hand, in this diagram, it can be seen that the difference in germination response of selected seeds in UHDs conditions is much more significant due to temperature and shows different and unique behavior. However, in untreated conditions, the difference in germination behavior is much smaller. It is also observed that increasing temperature causes $S$. officinalis to decrease while it decreases, decreasing the growth of $C$. roseus germination. Under these conditions, treatment of UHDs in both cases slightly helped to improve growth. However, the behavioral pattern did not change, and germination responded to temperature changes only with a lower slope (Figure 2a).

Figure $2 \mathrm{~b}$ shows the germination behavior under different irrigation conditions. The lowest seed germination rate increased ten times under UHDs conditions, and the maximum germination rate doubled compared to untreated conditions. For example, the lowest germination rate in untreated conditions related to $C$. roseus with a response of about 0.1 increased to 1.1 under UHDs treatment. Also, the highest germination response in untreated conditions is related to P. grandiflora with a response of about 1.29, which reached 2.34 under UHDs conditions. It is also observed that the rate of $R$. hirta germination increased with increasing irrigation in the presence of UHD's treatment. In general, $P$. grandiflora, S. officinalis, and C. roseus have better germination performance under UHDs and irrigation treatment (Figure 2b).

One of the Design-Expert software and RSM (or CCD) capabilities is to develop an equation that creates a three-dimensional behavioral curve of factors and allows the more accurate study and more realistic behavioral prediction. In Figures $2 \mathrm{c}$ and $2 \mathrm{~d}$, the three-dimensional seed germination behavior under temperature and irrigation treatment can be seen. In each diagram, the $\mathrm{X}$-axis represents the temperature variation levels, the Z-axis represents the irrigation variation levels, and the Y-axis represents the germination efficiency. The maximum points in these diagrams are the conditions in which the seeds have the highest germination efficiency. The spectrum color also represents the minimum / maximum range. Orange and red colors show maximum germination efficiency, blue colors show minimum efficiency, and green colors show middle germination efficiency (Figure 2c and 2d). As can be seen, $C$. roseus has very low germination efficiency in untreated conditions, which increases with 


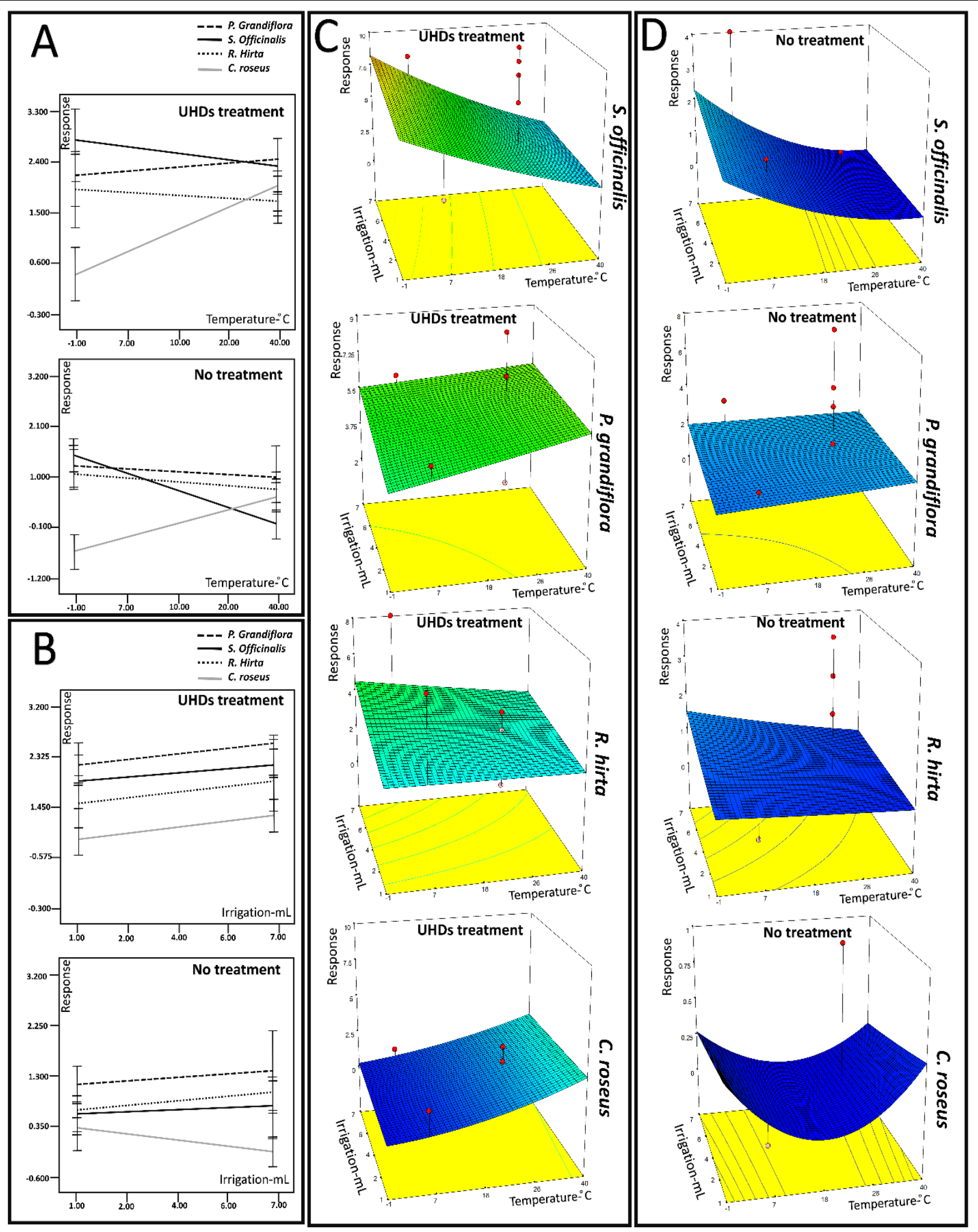

Fig 2 - Two-dimensional statistical study of the effect of (A) temperature and (B) irrigation, and (C and D) threedimensional statistical study of both temperature and irrigation parameters, under UHDs treatment compared to control conditions, on the germination efficiency of the studied plants. 
increasing temperature. At the same time, they have much higher efficiency under UHDs treatments, and the color spectrum changes from blue to green. All seeds have medium downward germination (blue) in untreated conditions, while under UHDs treatment, they move to medium upward germination (green and orange colors). Finally, the behavior of S.officinalis germination, which incompletely untreated conditions and a temperature of $40^{\circ} \mathrm{C}$ has become completely low efficiency and a temperature of $-1^{\circ} \mathrm{C}$ has become high efficiency (red). From Figure $2 \mathrm{c}$ and $2 \mathrm{~d}$, it is clear that in the case of UHDs, the highest germination efficiencies in S.officinalis at low temperature and high irrigation, and in $P$.grndiflora at high temperature and high irrigation. Also, germination efficiency in $R$. hirta at irrigation and medium temperature, and in C. roseus at high temperature and Irrigation occurs sparingly.

Table 3: ANOVA for the study of Rice seedling growth under the variety of treatments.

\begin{tabular}{|c|c|c|c|c|c|c|}
\hline Source & $\begin{array}{c}\text { Sum of } \\
\text { Squares }\end{array}$ & df & Mean Square & F Value & $\begin{array}{c}\text { p-value } \\
\text { Prob }>\text { F }\end{array}$ & \\
\hline Model & 90.93164 & 22 & 4.133256216 & 6.671839 & $<0.0001$ & significant \\
\hline A-Temp & 0.037643 & 1 & 0.037643338 & 0.060763 & 0.8058 & \\
\hline B-Wet & 0.13232 & 1 & 0.13231979 & 0.213589 & 0.6449 & \\
\hline C-Plant & 38.98576 & 4 & 9.746440986 & 15.73256 & $<0.0001 * *$ & \\
\hline D-Remedy & 30.62806 & 1 & 30.62805692 & 49.43934 & $<0.0001 * *$ & \\
\hline $\mathbf{A B}$ & 0.20245 & 1 & 0.202450396 & 0.326792 & 0.5688 & \\
\hline $\mathrm{AC}$ & 13.71102 & 4 & 3.4277555555 & 5.53303 & $0.0004 * *$ & \\
\hline AD & 0.10581 & 1 & 0.105809919 & 0.170797 & 0.6802 & \\
\hline BC & 0.277774 & 4 & 0.069443465 & 0.112095 & 0.9780 & \\
\hline BD & 0.01939 & 1 & 0.019389697 & 0.031299 & 0.8599 & \\
\hline CD & 4.436974 & 4 & 1.109243486 & 1.790524 & $0.1361 *$ & \\
\hline Residual & 66.28734 & 107 & 0.61950781 & & & \\
\hline Lack of Fit & 43.54189 & 65 & 0.669875201 & 1.23694 & 0.2329 & not significant \\
\hline Pure Error & 22.74545 & 42 & 0.541558276 & & & \\
\hline Cor Total & 157.219 & 129 & & & & \\
\hline Std. Dev. & 0.887088 & & R-Squared & 0.7578376 & & \\
\hline Mean & 1.029492 & & Adj R-Squared & 0.691687 & & \\
\hline
\end{tabular}

Response $^{\wedge}+1.03=-0.023 \times A+0.073 \times B+0.36 \times C[1]+0.76 \times C[2]-0.89 \times C[3]+0.29 \times C[4]-0.47 \times D-0.074 \times A \times B-0.68 \times$ $\mathrm{A} \times \mathrm{C}[1]+0.12 \times \mathrm{A} \times \mathrm{C}[2]+0.023 \times \mathrm{A} \times \mathrm{C}[3]-0.12 \times \mathrm{A} \times \mathrm{C}[4]-0.038 \times \mathrm{A} \times \mathrm{D}+0.018 \times \mathrm{B} \times \mathrm{C}[1]+0.019 \times \mathrm{B} \times \mathrm{C}[2]-0.062 \times \mathrm{B} \times$ $\mathrm{C}[3]+0.093 \times \mathrm{B} \times \mathrm{C}[4]-0.016 \times \mathrm{B} \times \mathrm{D}-0.22 \times \mathrm{C}[1] \times \mathrm{D}-0.047 \times \mathrm{C}[2] \times \mathrm{D}+0.34 \times \mathrm{C}[3] \times \mathrm{D}-1.817 \mathrm{E}-003 \times \mathrm{C}[4] \times \mathrm{Dif}: \mathrm{C}[1]: S$. officinalis, C[2] : P. grandiflora, C[3] : R. hirta, C[4] : C. roseus

After the statistical study of germination efficiency, the conditions under which the best germination occurs were selected, and the total protein and carbohydrate content and the hormonal variations were 
studied (Figure 3). The best germination rate for S.officinalis and R. hirta are $26^{\circ} \mathrm{C}$ and $6 \mathrm{ml}$ of irrigation. In the plant $C$. roseus, a temperature of $18{ }^{\circ} \mathrm{C}$ and $4 \mathrm{ml}$ of irrigation are the most suitable germination conditions (Figure 3a). In these cases, the production of total protein (Figure 3c) and carbohydrates (Figure 3b) as well as the levels of gibberellic acid (GA3 \& GA4), indole acetic acid (IAA), abscisic acid (ABA), and salicylic acid (SA), (Figure 3e, f \& g), under UHDs treatment compared to the untreated control condition, were studied. Due to the small size and impossibility of the chemical study, $P$. grandiflora was removed from this study stage. As shown in Figures $3 \mathrm{~b}$ and $3 \mathrm{c}$, in all studied plants, the amount of carbohydrate and protein production increases under UHD's conditions compared to the control conditions. The statistical study on the accuracy (mentioned in the previous section), $S$. officinalis, and $R$. hirta total carbohydrate and protein content increased significantly under UHDs conditions compared to the control conditions. While in the case of C. roseus, the increase is not statistically significant.

Figure 3d shows the standard chromatographic pattern of the hormones. In figures 3e, 3f, and $3 \mathrm{~g}$, the amount of these hormones can be seen in the UHDs treated samples (solid lines) compared to the untreated/control samples (dotted lines). As can be seen, the levels of hormones GA3 and IAA in all samples increase, and the amount of GA4 decreases. Also, the amount of ABA and SA hormones in $S$. officinalis increased under UHDs treatment while decreasing in the other two samples. It should be noted that the samples were selected from the optimal growth conditions and prepared in such a way that the final concentration was the same, and therefore the spectra were comparable.

\section{Discussion}

Following statistical studies, the effect of UHD's treatment on reducing stresses) temperature and irrigation) influence on seed germination was found that, in general, UHD's treatment lead to increase germination and growth and increase tolerance to stress conditions. In the case of $S$. officinalis, the effect of UHDs treatment on germination under stress conditions is noticeable (Figure 2c). Results show that both $S$. officinalis growth at high temperatures and $C$. roseus growth under higher irrigation condition has also improved, under UHDs treatment. As shown in figure 3a, the overall germination efficiency of seeds at low temperatures is negative or very low. At the same time, after treatment with UHDs, they presented an overall increase. A study of seed germination rate in selected conditions showed that primary root growth and primary seedling under UHDs treatment in $R$. hirta increased (Figure 3a). In previous studies, it was observed that the UHDs treatment leads to improved germination and survival of primary buds and increased production of primary metabolites [19]. Comparing the results of production of primary metabolites and hormone levels has shown that under the treatment of UHDs, the ability to seedlings growth and primary roots has improved. Accordingly, in all three plants, the amount of IAA hormone increased under UHDs treatment compared to the control conditions. IAA is responsible for stimulating the longitudinal growth of shoots and roots and inducing protein production [24-26]. Increased levels of this hormone match the results of physiological seed germination (Figure $3 a)$ and protein production (Figure 3c). The amount of GA3 responsible for increasing seed growth and the ability to use the nutrient content is increased [27]. In contrast, the level of GA4, which is responsible for cell differentiation [28,29], does not increase. Comparing the variations of these two and the variations in total free carbohydrate content (Figure 3b), it can be concluded that treatment of UHDs leads to stimulation and acceleration of growth, and the main focus is not on differentiation. The increments in ABA content which is the correspondence for further stimulates and accelerates rooting $[30,31]$ in S. officinalis, and its decrements in the other two samples is a sign of awakening and complete withdrawal of seed metabolism from dormancy. The levels of SA have also increased in $S$. officinalis treated using UHDs. This hormone stimulates and accelerates root growth, increases resistance to environmental stress, and initiates reactions to produce secondary metabolites and differentiation [32].

OPEN ACCESS 

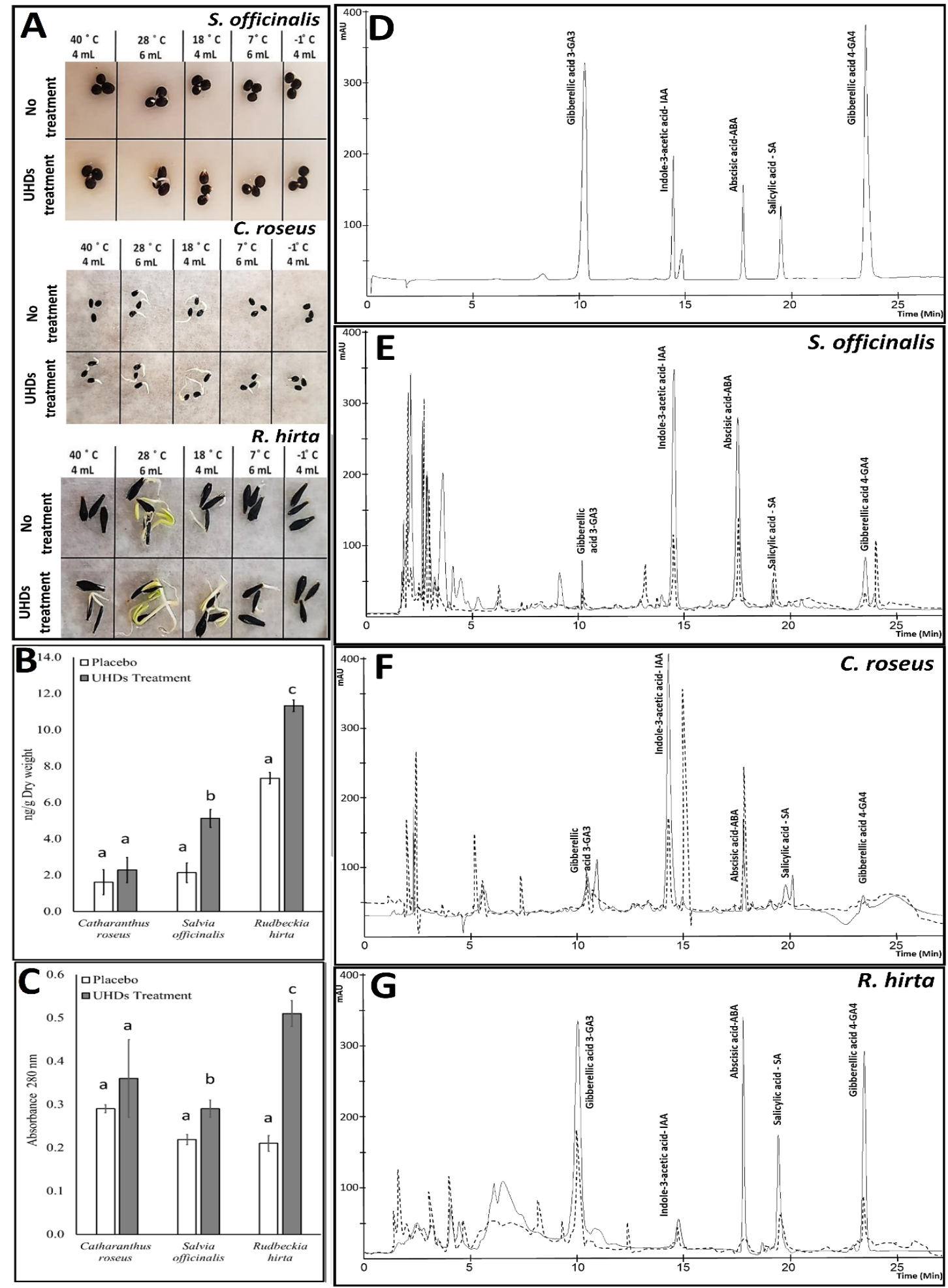

Fig 3 - The germination efficiency of selected seeds under the applied conditions. (A) The pattern of carbohydrate production (B), The pattern of protein production (C) and Chromatogram of germination extracts (E, F \& G) of optimal germination conditions under UHDs treatment (solid lines) compared to control conditions (dotted lines). Chromatogram of hormonal standard compounds (D). 


\section{Conclusions}

From the obtained results, it can be concluded that UHDs treatment generally leads to improved germination of seeds of selected ornamental plants, germination ability at very low or very high temperatures, and waterlogging or drought conditions have increased. Under the treatment of UHDs, the primary aerial and root growth is accelerated, as the quality of production of primary metabolites, including proteins and carbohydrates, is increased.

\section{Acknowledgments}

Financial support from The Shahid Beheshti University is gratefully acknowledged. This research project was sponsored by Shahid Beheshti University Research Council (Grant no. SAD/600/1450). The authors declare no conflicts of interest.

\section{References}

[1] Chen C, Wang B, Feng P, Xing H, Fletcher AL, Lawes RA. The shifting influence of future water and temperature stress on the optimal flowering period for wheat in Western Australia. Sci Total Environ. 2020;737:139707.

[2] Cammarano D, Ronga D, Di Mola I, Mori M, Parisi M. Impact of climate change on water and nitrogen use efficiencies of processing tomato cultivated in Italy. Agric Water Manag. 2020;241:106336.

[3] van Zonneveld M, Rakha M, Tan S yee, Chou Y-Y, Chang C-H, Yen J-Y, et al. Mapping patterns of abiotic and biotic stress resilience uncovers conservation gaps and breeding potential of Vigna wild relatives. Sci Rep. 2020;10(1).

[4] Nazemi Rafi Z, Kazemi F, Tehranifar A. Effects of various irrigation regimes on water use efficiency and visual quality of some ornamental herbaceous plants in the field. Agric Water Manag. 2019;212:78-87.

[5] Vosoughi N, Gomarian M, Ghasemi Pirbalouti A, Khaghani S, Malekpoor F. Essential oil composition and total phenolic, flavonoid contents, and antioxidant activity of sage ( Salvia officinalis L.) extract under chitosan application and irrigation frequencies. Ind Crops Prod. 2018;117:366-74.

[6] Eck MA, Murray AR, Ward AR, Konrad CE. Influence of growing season temperature and precipitation anomalies on crop yield in the southeastern United States. Agric For Meteorol. 2020;291:108053.

[7] Adnan M, Islam W, Shabbir A, Khan KA, Ghramh HA, Huang Z, et al. Plant defense against fungal pathogens by antagonistic fungi with Trichoderma in focus. Microb Pathog [Internet]. 2019;129:7-18. Available from: https://www.ncbi.nlm.nih.gov/pubmed/30710672

[8] de Queiroz VT, Azevedo MM, da Silva Quadros IP, Costa A V, do Amaral AA, Dos Santos $\mathrm{G}$, et al. Environmental risk assessment for sustainable pesticide use in coffee production. $\mathrm{J}$ Contam Hydrol [Internet]. 2018;219:18-27. Available from: 
https://www.ncbi.nlm.nih.gov/pubmed/30342837

[9] Lutz B, Heer I, Katzensteiner R, Raak C, Wolf U, Heusser P, et al. Development of a whole plant bioassay to test effects of potentized calcium carbonate in pillule formulation. Complement Ther Med [Internet]. 2018;40:13-21. Available from: https://www.scopus.com/inward/record.uri?eid=2-s2.0-

$85049875425 \&$ doi $=10.1016 \% 2 \mathrm{Fj}$. ctim.2018.06.005\&partnerID=40\&md5=06410d2e5f4a $6337 \mathrm{a} 43 \mathrm{a} 47 \mathrm{f} 45 \mathrm{e} 24 \mathrm{f} 983$

[10] Betti L, Trebbi G, Kokornaczyk MO, Nani D, Peruzzi M, Dinelli G, et al. Number of succussion strokes affects effectiveness of ultra-high-diluted arsenic on in vitro wheat germination and polycrystalline structures obtained by droplet evaporation method. Homeopathy [Internet]. 2017;106(1):47-54. Available from: https://www.scopus.com/inward/record.uri?eid=2-s2.085008430094\&doi=10.1016\%2Fj.homp.2016.12.001\&partnerID=40\&md5=f6459e6e218a 238faac660fb0c460b94

[11] Marotti I, Betti L, Bregola V, Bosi S, ... GT-E-B, 2014 undefined. Transcriptome profiling of wheat seedlings following treatment with ultrahigh diluted arsenic trioxide. hindawi.com [Internet]. [cited $2020 \quad$ Sep 24]; Available from: https://www.hindawi.com/journals/ecam/2014/851263/abs/

[12] Rissato BB, Stangarlin JR, Dildey ODF, Silva CR da, Gonçalves-Trevisoli EDV, ColtroRoncato S, et al. Fungitoxicity activity of Phosphorus and Calcarea carbonica against Sclerotinia sclerotiorum and control of white mold in common bean (Phaseolus vulgaris) with extremely diluted aqueous solutions. Aust J Crop Sci [Internet]. 2018;12(4):546-51. Available from: https:/www.scopus.com/inward/record.uri?eid=2-s2.085046868519\&doi=10.21475\%2Fajcs.18.12.04.pne804\&partnerID=40\&md5=8dacba10a $31712852519 f 2 f 3 a b 4 f 8585$

[13] Mioranza TM, Stangarlin JR, Müller MA, Coltro-Roncato S, Inagaki AM, Meinerz CC, et al. Control of Meloidogyne incognita in tomato plants with highly diluted solutions of Thuya occidentalis and their effects on plant growth and defense metabolism. Semin Ciências Agrárias [Internet]. 2017;38(4):2187. Available from: https://www.scopus.com/inward/record.uri?eid=2-s2.0$85027077257 \&$ doi $=10.5433 \% 2 \mathrm{~F} 1679$ 0359.2017v38n4p2187\&partnerID=40\&md5=425c8485a673d67c75151a9ce0d6bebf

[14] Mioranza TM, Inagaki AM, Müller MA, Stangarlin JR, Guimarães VF, Klein J, et al. Gas exchange and photosynthetic light response curves in nematode-infected tomato plants treated with Thuya occidentalis. Aust J Crop Sci [Internet]. 2018;12(4):583-91. Available from: https://www.scopus.com/inward/record.uri?eid=2-s2.0$85046875183 \&$ doi $=10.21475 \% 2$ Fajcs.18.12.04.pne861\&partnerID $=40 \& \mathrm{md} 5=45845 \mathrm{ffc} 04$ 31 bea4b7258c07ae976392

[15] Ezine NM-H, December undefined, 2008 undefined. Agro-Homeopathy-An Alternative for Agriculture. hpathy.com [Internet]. [cited 2020 Sep 24]; Available from: https://hpathy.com/homeopathy-papers/agro-homeopathy-an-alternative-for-agriculture/2/ 
[16] Scherer-Pongratz W, Endler PC, Lothaller H, Stephen S. Wheat and ultra high diluted silver nitrate - further experiments and re-analysis of data. Homeopathy [Internet]. 2015;104(4):246-9. Available from: https://www.scopus.com/inward/record.uri?eid=2s2.0-

84962692238\&doi=10.1016\%2Fj.homp.2015.09.009\&partnerID=40\&md5=7dbbf013f6f3 fb9c8fc8e9310700e2e9

[17] Endler PC, Scherer-Pongratz W, Lothaller H, Stephen S. Wheat and ultra high diluted gibberellic acid - further experiments and re-analysis of data. Homeopathy [Internet]. 2015;104(4):257-62. Available from: https://www.scopus.com/inward/record.uri?eid=2s2.0-

84949517440\&doi=10.1016\%2Fj.homp.2015.09.007\&partnerID=40\&md5=f475265ff87d 6fc17b90730e06700532

[18] Endler PC, Scherer-Pongratz W, Harrer B, Lingg G, Lothaller H. Amphibians and ultra high diluted thyroxine - further experiments and re-analysis of data. Homeopathy [Internet]. 2015;104(4):250-6. Available from: https://www.scopus.com/inward/record.uri?eid=2s2.0-

$84947607922 \&$ doi $=10.1016 \% 2 \mathrm{Fj}$. homp.2015.10.001\&partnerID=40\&md5=66f257fefc02 e3804cb373fd6f19bf8b

[19] Hosseinian S, Maute CC, Rahimi F, Maute CC, Hamedi M, Mirzajani F. The influence of ultra-high diluted compounds on the growth and the metabolites of Oryza sativa L. . Int J High Dilution Res. 57th ed. 2020;19(3):39-57.

[20] (Suppl) SM-A, 2016 undefined. Agrohomeopathy-new practice in agriculture from seed germination to field trial.

[21] Fu J, Xiaohong S, Wang J, Jinfang C, Cunyu Y. Progress in quantitative analysis of plant hormones. Chinese Sci Bull [Internet]. 2011 Feb [cited 2020 Sep 24];56(4):355-66. Available from: www.springer.com/scp

[22] Pan X, Welti R, protocols XW-N, 2010 undefined. Quantitative analysis of major plant hormones in crude plant extracts by high-performance liquid chromatography-mass spectrometry. nature.com [Internet]. [cited 2020 Sep 24]; Available from: https://www.nature.com/nprot/journal/v5/n6/full/nprot.2010.37.html

[23] Waadt R, Hsu PK, Schroeder JI. Abscisic acid and other plant hormones: Methods to visualize distribution and signaling. Bioessays [Internet]. 2015;37(12):1338-49. Available from: https://www.ncbi.nlm.nih.gov/pubmed/26577078

[24] Liang C, Liu H. Response of hormone in rice seedlings to irrigation contaminated with cyanobacterial extract containing microcystins. Chemosphere [Internet]. 2020;256:127157. Available from: https:/www.ncbi.nlm.nih.gov/pubmed/32470740

[25] Safdarian M, Askari H, Nematzadeh G, Sofo A. Halophile plant growth-promoting rhizobacteria induce salt tolerance traits in wheat seedlings (Triticum aestivum L.). Pedosphere. 2020;30(5):684-93.

[26] Rushabh S, Kajal C, Prittesh P, Amaresan N. Isolation, characterization, and optimization

OPEN - ACCESS 
of indole acetic acid - producing Providencia species (7MM11) and their effect on tomato ( Lycopersicon esculentum ) seedlings . Biocatal Agric Biotechnol . 8th ed. 2020;28(1).

[27] Ma HY, Zhao DD, Ning QR, Wei JP, Li Y, Wang MM, et al. A Multi-year Beneficial Effect of Seed Priming with Gibberellic Acid-3 (GA3) on Plant Growth and Production in a Perennial Grass, Leymus chinensis. Sci Rep [Internet]. 2018;8(1):13214. Available from: https://www.ncbi.nlm.nih.gov/pubmed/30181574

[28] Hisamatsu T, Koshioka M, Kubota S, Fujime Y, King RW, Mander LN. The role of gibberellin biosynthesis in the control of growth and flowering in Matthiola incana. Physiol Plant. 2000 May;109(1):97-105.

[29] Rademacher W. Chemical Regulators of Gibberellin Status and Their Application in Plant Production. 2017;359-403.

[30] Worarad K, Xie X, Martha Rumainum I, Burana C, Yamane K. Effects of Fluridone Treatment on Seed Germination and Dormancy-associated Gene Expression in an Ornamental Peach Prunus persica (L.) Batsch. Hortic J. 2017;86(3):317-26.

[31] Krisantini, Wiendi NMA, Palupi ER. Evaluation of horticultural traits and seed germination of Tacca chantrieri 'André. Agric Nat Resour. 2017;51(3):169-72.

[32] Kondratieva V V, Voronkova T V, Olekhnovich LS, Bidyukova GF, Enina OL, Shelepova O V. The Spectral Light Influence on Young Ornamental Plants' Resistance to Short-Term Cold Stress. Sel'skokhozyaistvennaya Biol. 2019;54(1):121-9.

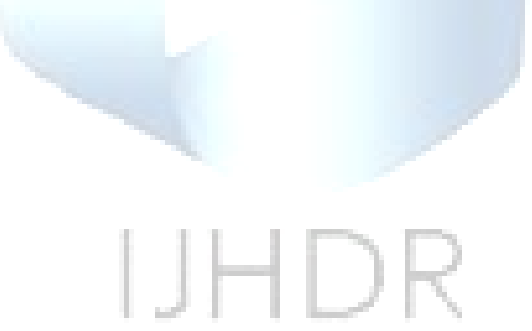

Received: Nov 11, 2020. Accepted: Jan 31, 2021.

(C) International Journal of High Dilution Research.

Not for commercial purposes. 